\title{
Corporeidades Mestiças: Pesquisa Somático- Performativa como uma opção descolonial
}

SERRANO, Leonardo Sebiane. ${ }^{1}$

Resumo:

O texto discute o princípio de corporeidade e(m) mestiçagem para as artes (cênicas/performáticas), sob os princípios do Manifesto da Pesquisa Somático-Performativa apresentado no VII Congresso da Associação Brasileira de Pesquisa e PósGraduação em Artes Cênicas, em 2012, na cidade de Porto Alegre, pela Profa. Dra. Ciane Fernandes; (re)vistos como uma opção descolonial, para a pesquisa/criação artística e acadêmica nas artes cênicas e performativas na atualidade. Discute a necessidade e a possibilidade de (re)considerar novos olhares, estéticas e poéticas para a pesquisa/criação em artes, a partir da Pesquisa Somático-Performativa, das interfases destas corporeidades mestiças e da desobediência epistêmica, proposta na opção descolonial.

Palavras-chave:

Corporeidades; Pesquisa Somático-Performativa; Opção Descolonial.

\section{Abstract:}

This article discusses the principle of corporality and/in miscegenation for the Arts (scene-performance), under the Manifest of Somatic-Performance Research principles, (re)viewed as an option decolonial, for artistic research/creation and background in the scene/performance arts today. Thus, as discussed the necessity and possibility of (re)consider points of view, aesthetic and poetic for research/creation in arts, under the Somatic-Performative Research, interphases of these corporalities and epistemic disobedience, as proposed in decolonial option.

Keywords:

Corporalities; Somatic-Performance Research; Decolonial Option.

Doutor em Artes Cênicas pelo Programa de PósGraduação em Artes Cênicas da Universidade Federal da Bahia (PPGAC/ UFBA). E-mail: leosebiani@gmail.com 
A palavra corpo é, por vezes, utilizada com certa fixidez que não é compatível com a prática vivencial do mesmo; portanto, assim como a subversão na categoria "corpo" que propõe Michel Bernard, à luz dos estudos de Merleau-Ponty, entende-se que este assunto interessa a artistas-pesquisadores como uma forma de apropriação.

Subverter radicalmente a categoria tradicional de "corpos" ao propor uma visão original, ao mesmo tempo plural, dinâmica e aleatória, como jogo quiasmático instável de forças intensivas ou vetores heterogêneos. Visão que é conveniente designar a partir de agora pelo vocábulo de conotações mais plásticas espectrais de "corporeidade" (BERNARD, 2001, p. 22).

A designação de corporeidade foi usada antes por vários autores e propõe uma relação entre natureza e cultura, signos e codificações de informações que se comunicam, se configuram, se reorganizam, em um complexo sistema dinâmico de evolução (CONRADO, 2008). Entendendo essa evolução como um processo de mudança, sem chegar a colocar pré-concepções sobre essas mutações, a autora Suely Rolnik descreve o que ela denomina como "movimento constante e vibrátil”:

(...) "vibrátil", que faz com que o olho seja tocado pela força do que vê. Sem muita dificuldade, logo notamos que a densidade desta pele é ilusória e efêmero é o perfil que ela envolve e delineia. A pele é um tecido vivo e móvel, feito das forças/fluxos que compõem os meios variáveis que habitam a subjetividade: meio profissional, familiar, sexual, econômico, político, cultural, informático, turístico, etc. Como estes meios, além de variarem ao longo do tempo, fazem entre si diferentes combinações, outras forças entram constantemente em jogo, que vão misturar-se às já existentes, numa dinâmica incessante de atração e repulsa. Formam-se na pele constelações as mais diversas que vão se acumulando até que um diagrama inusitado de relações de força se configure. Nesse momento, nosso olho vibrátil capta na pele uma certa inquietação, como se algo estivesse fora do lugar ou de foco (ROLNIK, 2013b).

Esta subversão da categoria é potencializada no âmbito das artes cênicas e performáticas, que nos aproxima dos processos de criação/descoberta de uma arte viva, contínua, mutável e inacabada, uma arte com um corpo vibrátil, sem órgãos e intensivo na existência do artista. 
Este plano é o "corpo vibrátil", no qual o contato com o outro, humano e não humano, mobiliza afetos, tão cambiantes quanto a multiplicidade variável que constitui a alteridade. A constelação de tais afetos forma uma realidade sensível, corpórea, que, embora invisível, não é menos real do que a realidade visível e seus mapas. É o mundo compondo-se e recompondo-se singularmente na subjetividade de cada um. Muda o mundo, muda a consistência sensível da subjetividade, indissociavelmente: entre eu e o outro, desencadeiam-se devires não paralelos de cada um, num processo sem fim. É a partir da escuta do corpo vibrátil e suas mutações, que o artista, desassossegado pelo conflito entre a nova realidade sensível e as referências antigas de que dispõe para orientar-se na existência, sente-se compelido a criar uma cartografia para o mundo que se anuncia, a qual ganha corpo em sua obra e dele se autonomiza (ROLNIK, 2000).

Nessas corporeidades tem-se a comprovação artística das sensibilidades e das subjetividades dos artistas, elementos poucas vezes contemplados e que deixam um rastro na sua arte. Esse movimento faz-se interessante para artistas-pesquisadores à medida que se configura como um movimento nas contradições, nas misturas e num contínuo (re)fazer.

\section{Hibridismo ou Mestiçagem}

Uma corporeidade tal como descrito por Rolnik sustenta o movimento constante das (inter)relações sociopsicoculturais e tem relevância quando se pensa em um continente no qual as migrações e o nomadismo têm sido frequentes, no qual é importante (re)entender esse corpo diferenciado, tendo em vista um olhar que está se transformando desde o período colonial e que vem se fortalecendo, cada vez mais, nas misturas das culturas, entendidas por culturas de fronteira.

As hibridações [...] nos levam a concluir que hoje todas as culturas são de fronteira. Todas as artes se desenvolvem em relação com outras artes: o artesão migra do campo para cidade; os filmes, os vídeos e canções que narram acontecimentos de um povo são intercambiados com outros. Assim as culturas perdem a relação exclusiva com seu território, mas ganham em comunicação e conhecimento (CANCLINI, 2008, p. 348).

Assim, as hibridações em nossos povos geram uma constante troca, ganhando conhecimento. Essa comunicação constante permite que a contaminação seja mais rápida, criando pluriculturas, nas quais o corpo já não é um território conhecido: ele se faz mais complexo nas noções de cultura-identidade, mas sempre tendo um rastro, uma estrutura em processo que gera uma história - a sua própria história. 
Uma história da América Latina que estimula o contínuo "caos" de criação e recriação; uma história que, na sua transcendência, permeia o corpo, princípio que ecoa na "transcendência para que aponta toda a arte barroca que implica um outro corpo: ágil, leve, esculpido pela tentação, em tensão permanente. Um corpo em festa, animado pela paixão" (SARDUY, 1988, p. 16). Um corpo que é movimentado pela paixão é um corpo rico e aberto às informações em todo tipo de relações.

Além da simples hibridação, como assinala Pinheiro, esse corpo está em contínua mestiçagem:

A mestiçagem se constitui como uma trama relacional, conectiva, cujos componentes não remontam saudosa e solitariamente a instâncias aurorais perdidas, mas sim festejam o gozo sintático dessa tensão relacional que se mantém como ligação móvel em suspensão (PINHEIRO, 2006, p. 6).

O continente americano tende a misturar e fazer coexistirem as categorias de mestiçagem e hibridismo, ao mesmo tempo em que o étnico, no nosso cotidiano e nas telas de nossos televisores, não passa de um indício da confusão que reina nos espíritos. O fenômeno também demonstra o aparecimento, segundo Gruzinski (2001), de um "idioma planetário", gerado na mistura de seres humanos e dos imaginários que é chamada de mestiçagem. Misturar, mesclar, amalgamar, cruzar, interpenetrar, superpor, imbricar, colar, fundir. Uma impressividade e uma indefinição do pensamento que vai do "homogêneo" ao "heterogêneo" com características nômades e sincréticas, com natureza dinâmica, em constante mutação, assim como em suas várias características (fluxo, dinamismo, inacabado, contaminações, interações múltiplas, imprevisibilidade, complexidade, imprevisto, aleatório etc.).

A palavra "mestiçagem" é empregada, neste artigo, em consonância com o pensamento de Gruzinski (2001), para quem o termo serve para designar as misturas que ocorreram em solo americano no século XVI entre seres humanos, imaginários e formas de vida vindos de quatro continentes -América, África, Ásia e Europa. Quanto ao termo "hibridação", aplica-se, neste texto, às misturas que se desenvolveram dentro de uma mesma civilização ou de um mesmo conjunto histórico - a Europa cristã, a MesoAmérica - e entre tradições que, muitas vezes, coexistem há séculos. Mestiçagem e hibridação dizem respeito tanto aos processos objetivos, observáveis em fontes variadas, como à consciência que têm deles os atores do passado, podendo 
essa consciência se expressar tanto nas manipulações a que eles se dedicam, como nas construções que elaboram ou nos discursos e condenações que formulam.

Uma corporeidade mestiça e um "idioma planetário" são a herança de uma América Latina intercultural, em um lugar no qual se revela a alta complexidade em que convivemos. Uma complexidade que é inerente ao ser humano, conforme aponta Morin: "(...) como tudo que é humano, a unidade do pensamento complexo é uma e múltipla e comporta em si a multiplicidade, assim como a multiplicidade comporta a unidade" (MORIN, 2002). A corporeidade, como unidade, corresponde às suas multiplicidades que, unidas a redes de informações, se complexifica cada vez mais nos processos culturais, assim como nos processos criativos das consciências mestiças.

\section{Corporeidades Mestiças}

Ao falar de corporeidades pode-se dar uma maleabilidade para significar as relações do performer com o externo/ interno: um corpo/meio e sujeito/objeto é, agora, desmaterializado em corporeidades mutáveis, num entendimento somático das relações vibráteis. É pelo aglomerado de diferenças que parece constituir o que se define por "corporeidade mestiça", a partir da mistura com diversos sistemas de ordem topográfica e geológica, ou seja, ambiental, em diálogo com heterogeneidades (CONRADO, 2008).

O interculturalismo funcional responde, em parte, aos interesses e às necessidades das instituições sociais; a interculturalidade crítica, por sua vez, é uma construção de e desde as pessoas que têm sofrido uma história do submetimento e subalternização (WALSH, 2010). Essa cultura latino-americana incorpora as retículas de suas camadas dos processos interculturais inerentes a toda sua história de troca e mestiçagem, uma verdadeira intercultura, que foi, e é, uma rede de complexidades inscritas nos corpos mestiços de seus habitantes.

É na complexidade dessa corporeidade mestiça que o psíquico, o emocional, o cognitivo e suas identificações individuais conformam a corpografia. Entendendo que esses fatores influenciam diretamente nosso agir na cotidianidade e, explicitamente, nas artes cênicas, nas quais se trabalha com o corpo como sujeito de criação, vê-se um corpocultura, que é objeto deste texto, e corpografias mestiças de sujeitos nos processos criativos nas artes cênicas (SEBIANESERRANO, 2010). 
Assim, cria-se uma consciência mestiça como possibilidade de sentir a fratura entre ser e estar; uma sensação de estar fora do lugar; mas, ligando ambos, a correlação entre espaço e a densidade da vida orgânica (pampas, montanhas, selvas, florestas, rios etc.) com cidades espalhadas e baixa densidade demográfica.

\section{Opção Descolonial}

Para estudar os processos socioculturais e de construções de imaginários na América Latina, é importante discutir desde onde são colocados os olhares do artista-pesquisador, sobretudo pelo fato de que o pensamento colonial ainda possui força nas trajetórias e imaginários de alguns habitantes da América Latina. A maioria dessas raízes imaginárias vem se sustentando em mecanismos científicos, nos quais o pesquisador acredita ser neutro e sem visão alguma que o contamine; mas elas possuem, sim, um pensamento muitas vezes eurocêntrico e racista.

Muito por cima das ciências sociais e da antropologia cultural do século XIX, foram as próprias ciências naturais, petrechadas com uma linguagem e um método praticamente blindados a toda crítica extracientífica, quem fez do estigma racial um dogma verdadeiramente inquestionável o final do século XIX. Porém da eurocêntrica etnologia do período, assim como do tão traído e levado darwinismo social, foi a própria biologia humana - em concreto, através de seu discursos sobre a evolução diferencial das raças -, a encarregada de dar seu mais sólido sustém teórico ao racismo implícito na expansão imperialista do ocidente finissecular ${ }^{2}$ (SANCHEZ-ARTEAGA, 2008, p. 122, tradução livre).

Essa diferença das raças que se pretendeu justificar na ciência constitui um rastro e ressonância em muitas das ações dos corpos latinos, mas pode-se optar pela opção descolonial, que se desvincula dos fundamentos genuínos dos conceitos ocidentais e da acumulação de conhecimento. Por desvinculamento epistêmico não se pretende dizer abandono ou ignorância do que já foi institucionalizado por todo o planeta; consequentemente, a opção descolonial significa, entre outras coisas, aprender a desaprender (MIGNOLO, 2011).

O pensamento descolonial, segundo Mignolo, significa também o fazer descolonial, já que a distinção moderna entre teoria e prática não se aplica quando se entra no campo do pensamento da fronteira e nos projetos descoloniais, quando se entra no campo do quichua e quechua, aymara e tojolabal, árabe e bengali etc. Categorias de pensamento
2.

No original: "Muy por encima de las ciencias sociales y de la antropología cultural decimonónicas, fueron las propias ciencias naturales, pertrechadas con un lenguaje y un método prácticamente blindados a toda crítica extracientífica, quienes hicieron del estigma racial un dogma verdaderamente incuestionable a fines del siglo XIX. Más allá de la eurocéntrica etnología del periodo, así como del tan traído y llevado darwinismo social 11, fue la propia biología humana - en concreto, a través de su discurso sobre la evolución diferencial de las razas-, la encargada de dar su más sólido sostén teórico al racismo implícito en la expansión imperialista del occidente finisecular" (SANCHEZARTEAGA, 2008, p. 122). 
confrontadas, claro, com a expansão implacável dos fundamentos do conhecimento do ocidente (ou seja, latim, grego), ou, pode-se dizer, da epistemologia.

Na América do Sul, na América Central e no Caribe, o pensamento descolonial vive nas mentes e nos corpos de indígenas, bem como nos de afrodescendentes. As memórias gravadas em seus corpos por gerações e a marginalização sociopolítica à qual foram sujeitos por instituições imperiais diretas, bem como por instituições republicanas controladas pela população crioula dos descendentes europeus, alimentaram uma mudança na política e geopolítica de estado de conhecimento. O "pensamento descolonial castanho", segundo o mesmo Mignolo (2008), foi construído nos Palenques, nos Andes e nos quilombos no Brasil, por exemplo, complementou o "pensamento indígena descolonial" trabalhando como respostas imediatas à invasão progressiva das nações imperiais europeias (Espanha, Portugal, Inglaterra, França, Holanda).

As opções descoloniais e o pensamento descolonial têm uma genealogia de pensamento que não são fundamentadas nas línguas greco-latinas, mas que foram agrupadas na língua imperial regional, e que reemergiram no pensamento e no fazer descolonial verdadeiro: Candomblés, Santería, Vudú, Rastafarianismo, Capoeira etc.

Após o fim do século XVIII, as opções descoloniais se estenderam para vários locais na Ásia (do Sul, do Leste e Central) até a Inglaterra e a França, principalmente, e assumiram a liderança da Espanha e de Portugal dos séculos XVI ao XVIII. O pensamento descolonial é a estrada para a pluri-versalidade como um projeto universal, à medida que implica pensar a partir das línguas e das categorias de pensamento não incluídas nos fundamentos dos pensamentos ocidentais.

Segundo Mignolo (2011), os quatro âmbitos em questão, descritos sucintamente, são os seguintes: 1) gestão e controle das subjetividades (por exemplo, a educação cristã e laica, ontem e hoje, os museus e as universidades, os meios de comunicação e a publicidade atuais etc.); 2) gestão e controle da autoridade (por exemplo, os vice-reinados nas Américas, a autoridade britânica na Índia, o exército estadunidense); 3) gestão e controle da economia (por exemplo, por meio da reinversão dos benefícios obtidos com apropriação massiva de terras na América e na África; a dívida externa por meio da criação de instituições econômicas como o Banco Mundial e o FMI); e 4) gestão e controle do conhecimento 
(por exemplo, a teologia e a invenção do direito internacional, que estabeleceram uma ordem geopolítica do conhecimento baseado nos princípios epistêmicos e estéticos europeus que, durante séculos, legitimaram a desautorização do conhecimento não europeu e dos cânones estéticos não europeus, desde o Renascimento até a Ilustração e desde a Ilustração até a globalização neoliberal).

Esses quatro âmbitos estão constantemente inter-relacionados e é preciso lembrar que cada um deles se oculta atrás da máscara de uma retórica da modernidade constante e cambiante que apregoa a salvação, o progresso, o desenvolvimento e a felicidade.

Como assegura Bautista (2013), é desta forma que se torna importante pensar "desde", pois é próprio do logos exercer o pensar; isto é, quando se quer meditar profundamente sobre o porquê de algo é preciso partir da preeminência da realidade como complexidade além de qualquer sistema teórico. Ao contrário, o pensamento "para" já não é próprio do pensar, porque supõe a relação sujeito-objeto intrínseca à modernidade. O sujeito pensa "para" o objeto porque, para o sujeito, o objeto, por princípio, não pensa. O pensamento moderno-ocidental tem se constituído como um pensamento "para" porque pensa a si mesmo como sujeito capaz de colocar-se no lugar da humanidade toda, na qual tem-se constituído em objeto.

Por esta razão o pensamento "desde" supõe a incorporação plena da relação categorial sujeito-sujeito, a qual, por sua vez, supõe a incorporação categorial do princípio "reconhecimento" da vítima como corporalidade negada e o reconhecimento do princípio "liberação" como intencionalidade ético-crítica de toda dominação sistêmica. Somente desde o pressuposto do pensar "desde" pode-se considerar a possibilidade de "pensar com", porque primeiro é preciso tirar julgamentos desde a realidade do outro, para, então, poder dialogar e pensar com o outro.

\section{Pesquisa Somático-Performativa}

Segundo Haseman (2006), a pesquisa performativa pode ser entendida como um espaço no qual a abordagem da pesquisa se informa e se forma a partir da prática performática e vice-versa. Isto é afirmado por Fernandes, para quem, na Pesquisa Somático-Performativa (PSP), o corpo possui uma importância nas construções/procuras dos caminhos da pesquisa. 
A PSP pode ser entendida como aquela em que "(...) o corpo é autor, criador e pesquisador; estudo, estudado e estudante, é o meio, é o fim; tema e método, quem, o que, como e onde" (FERNANDES, 2008, p. 3); assim, permite que, nas artes cênicas, aquilo que seria "objeto" seja visto como sujeito num corpo em movimento, o que permite a (re)apropriação de uma consciência em mudança constante.

O movimento - assim como sua análise e descrição - não pode ser percebido como um quadro ou sequência de quadros, mas sempre como um continuum em desenvolvimento, organizado em formatos imprevisíveis de preparo, ação principal, e uma continuação ou recuperação - que pode ser uma transição para outro preparo, ou já para outra ação (...). Isto é particularmente relevante quando lidamos com qualidades dinâmicas - fluxo, peso, foco, tempo - pois tudo passa a ser entendido como energia e(m) fluxo, de modo visível ou subliminar (...). Mesmo o espaço é compreendido como percursos de energia em gradações entre contrastes (FERNANDES 2010a, p. 4).

A ideia de corpografias está delineada na tese de doutorado intitulada Corpografias: uma leitura corporal dos intérpretes criadores do grupo Dimenti (SEBIANE-SERRANO, 2010) como arquiteturas efêmeras que suportavam a subpartitura dos intérpretes-criadores, estruturas dinâmicas que servem para (re)entender os processos criativos e suas inter-relações.

A estabilidade não advém de um estado de rigidez e controle. Muito pelo contrário, é exatamente a mobilidade, alcançada a través do Princípio como as Correntes Cinestésicas (Kinetic Chains), a rotação gradual ou da relação (forma), entre contrastes e categorias, que se cria uma estabilidade (intrinsecamente) dinâmica (FERNANDES, 2010b, p. 37).

A ideia de uma estabilidade dinâmica e compartida no inacabado da obra artística cênica e performática estabelece estruturas modulares intrinsecamente relacionadas com o processo de criação, e essa mobilidade de pesquisa e(m) ação é vivenciada pelos artistas do corpo. As corpografias, vistas como um acervo em contínua transformação, têm uma relação estreita com o dinamismo em que a PSP se baseia.

\section{Corporeidades Mestiças: Possiveis Olhares}

Nos caminhos da arte pode-se falar de corporeidades mestiças como corpografias, arquiteturas efêmeras, parte da arte inacabada, fruto da antropofagia e de processos mobilizadores que são parte da dinâmica vibrante e frágil 
da mestiçagem (LEPLANTINE, 1997). Essas corporeidades, como possíveis olhares, criam novas possibilidades estéticas - sendo a estética, aqui, entendida como conceito secular da razão -, que cumprem duas funções complementares: A) na Europa, começa-se a construir uma subjetividade secular e burguesa que se separa da subjetividade sacra e teológica construída a partir do Renascimento e liderada pelos países do sul; e B) fora da Europa, a estética emerge como um novo conceito e critério de (re)avaliar e hierarquizar a criatividade sensorial das outras civilizações (MIGNOLO, apud PALERMA, 2009).

As estéticas descoloniais e de resistência convidam o artista pesquisador a desaprender para iniciar um caminho por outras aprendizagens, nos quais se possa desvelar a existência de formas diferentes de ver o mundo e de pintá-lo com diversas cores, o que constitui nada além da expressão dos numerosos processos que estão acontecendo em diversas partes da América e do mundo e não pode ser negligenciado: é prioritário mostrar tais possibilidades para poder aceder a elas como fonte de produção de conhecimento (ACHINTE, 2011).

Pode-se conciliar com o local em que nos coloca Rolnik (2013b): uma linha fronteiriça e uma subjetividade que não se encontram nem prisioneiras de uma forma, como na neurose, nem perdidas nas intensidades do corpo-vibrátil, como na psicose; funâmbula, a estética descolonial se equilibra, bem ou mal, na fronteira. Em precária posição, há uma espécie de fluidez no processo, embora esteja sempre presente o risco de cair. Se a queda é para o lado da neurose, há uma parada do processo; se ela é para o lado da psicose, o processo fica rodando no vazio, no infinito.

É com esse infinito de possíveis olhares que a Pesquisa Somático-Performativa vira uma opção descolonial, como uma outra possibilidade de conhecimento: o conhecimento das corporeidades, suas possibilidades, estéticas e poéticas; no caso da America Latina, rico em mestiçagem/hibridação, ou seja, corpografias em estados de borderline contínuos. 


\section{REFERÊNCIAS}

ACHINTE, Adolfo Albán. Estéticas decoloniales, estéticas de re-existencia: entre memorias y presencias afrodescendientes. In: HAIDAR, Julieta; SÁNCHEZ, Graciela Guevara (eds.). La arquitectura del sentido II. La producción y reproducción en las prácticas semiótico-discursivas. Instituto Nacional de Antropología e Historia, México, 2011.

BAUTISTA, Juan Jose. ¿Que Significa Pensar desde América Latina? In: AFLY (Asociación de Filosofía y Liberación). Disponível em: http://www.afyl.org/quesignificapensar.pdf Acesso em: 5 fev. 2013.

BERNARD, Michel. De la création choréografique. Paris, Centre National de la Danse (CND), 2001.

CANCLINI, Néstor Garcia. Culturas híbridas. São Paulo: EDUSP, 2008.

CONRADO, Margarete. Corpo Mestiço: Metáforas do encontro sagrado e profano nos cortejos do Maracatú Nação. In: IV ENECULT: Encontro de Estudos Multidisciplinares em Cultura, Faculdade de Comunicação, UFBA: 2008.

FERNANDES, Ciane. Entre Escrita Performativa e Performance Escritiva: O Local da Pesquisa em Artes Cênicas com Encenação. In: V Congresso ABRACE. Belo Horizonte: Abrace, 2008.

Pela Câmera Somática: A Dança-

Teatro e o Vídeo-Documentario como Performance. In: Revista Contemporânea. Faculdade de Comunicação da UFBA. v. 8, 2010 .

Criatividade, Conexão e Integração: Uma introdução à obra de Irmgard Bartenieff. In: Em Pleno Corpo: Educação Somática, Movimento e Saudê. Debora Pereira Bolsanello, org. $2^{\text {a }}$ ed. v.1. Curitiba: Juruá, 2010b, 34-48.

GRUZINSKI, Serge. O pensamento mestiço. Traduzido por Rosa Freire d'Aguiar. São Paulo: Companhia das Letras. 2001.

HASEMAN, Brad. Manifesto for Performative Research. In: Media International Australia incorporating Culture and Policy. n. 118, Febrary 2006, pp.98-106.

LEPLANTINE, François; NOUSS, Alexis. Le Métissage. France: Dominos Flammarion. 1997.

PINHEIRO, Amalio. Introdução em comunicação e cultura: barroco e mestiçagem. Campo Grande: Uniderp, 2006.

MIGNOLO, Walter. Desobediência Epistêmica: A opção descolonial e o significado de identidade em política. Traduzido por: Ângela Lopes Norte. Caderno das Letras da UFF, Dossiê: Literatura, língua e identidade, n. 34, p287-324. 2008. 
La colonialidad: La cara oculta de la modernidad. IN: América Latina lo contrario. USA: Duke University Press, 2011.

In PALERMO, Zulma. Arte y Estética en la encrucijada descolonial/compilado por Zulma Palermo. Buenos Aires: Del Signo, 2009.

MORIN, Edgar. Abertura. In: DE CASTRO, Gustavo. Ensaios de Complexidade. Porto Alegre: Meridional Ltda., 2002.

ROLNIK, Suely. O Corpo Vibrátil de Lygia Clark. Folha de São Paulo: Domingo 30 de abril de 2000.

Lygia Clark e o Híbrido arte/clínica. Disponível em: http://www.caosmose.net/suelyrolnik/pdf/Artecli.pdf Acesso em: 8 fev. 2013 .

Uma insólita viagem à subjetividade fronteiras com a ética e a cultura. Disponível em: http://www.caosmose.net/ suelyrolnik/pdf/sujeticabourdieu.pdf Acesso em: 8 fev. 2013b.

SÁNCHEZ-ARTEAGA, Juan Manuel. La biología humana como ideología: el racismo biológico y las estructuras simbólicas de dominación racial a fines del siglo XIX. THEORIA, 2008.

SARDUY, Severo. Barroco. Tradução de María de Lurdes Júdice e José Manuel de Vasconcelos. Lisboa: Vega Limitada, 1988.

SEBIANE-SERRANO, Leonardo. Corpografias: uma leitura corporal dos intérpretes criadores do grupo Dimenti. Tese de doutorado do Programa de Pós-graduação em Artes Cênicas da Universidade Federal da Bahia. Salvador: Bahia, 2010.

WALSH, Caterine. Interculturalidad crítica y pedagogía de-colonial: In-surgir, re-existir y re-vivir, entrepalabras. In: Revista de Educación en el Lenguaje, la Literatura y la Oralidad (La Paz: Universidad Mayor San Andrés), nº 3-4, Feb. 2010. 